\title{
Author Correction: A comprehensive metabolic map for production of bio-based chemicals
}

Sang Yup Lee (iD, Hyun Uk Kim (D), Tong Un Chae, Jae Sung Cho (iD, Je Woong Kim, Jae Ho Shin (D), Dong In Kim, Yoo-Sung Ko, Woo Dae Jang (D) and Yu-Sin Jang (iD)

Correction to: Nature Catalysis https://doi.org/10.1038/s41929-018-0212-4, published online 14 January 2019.

In the version of this Review Article originally published, some chemical structures were incorrect: in Fig. 1, polyamide 4, polyamide 4,6 and polyamide 6,5; in Fig. 2, fumarate. Many structures were also incorrect in Supplementary Data 1. All of these errors have now been corrected in the original Review Article, and the changes to the structures are shown in the versions of Fig. 1, Fig. 2 and Supplementary Data 1 in this notice.
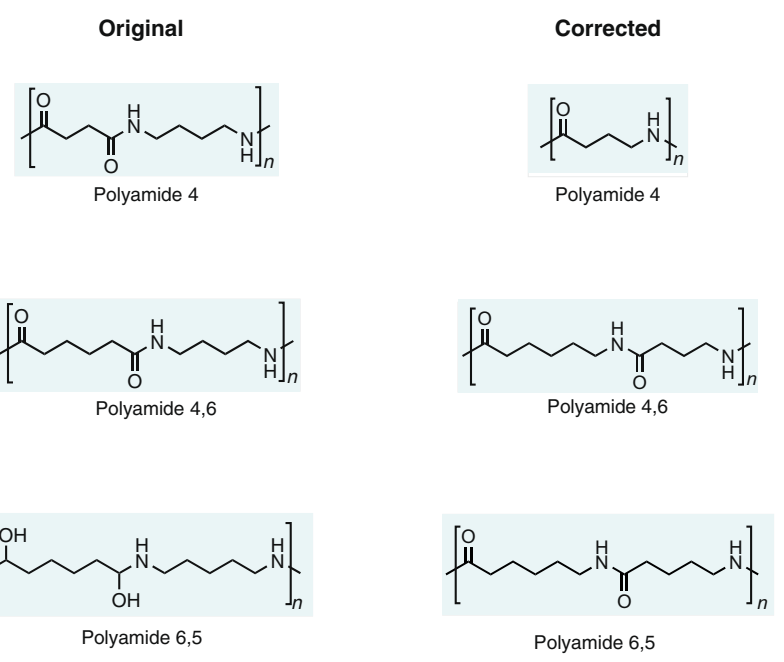

Fig. 1 | Original and Corrected.

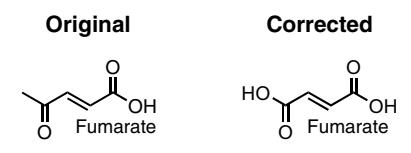

Fig. 2 | Original and Corrected. 


\section{Original}
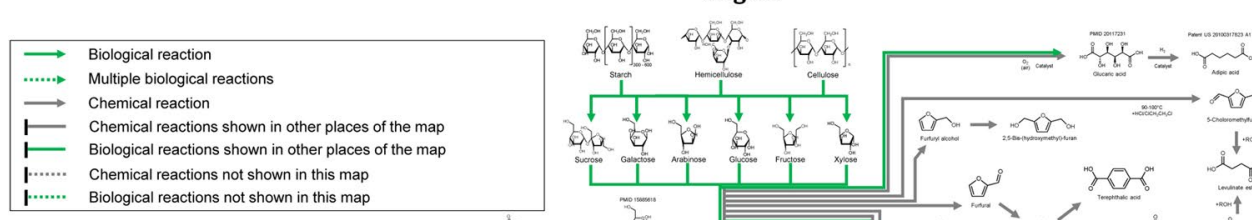

F...... Biological reactions not shown in this map b 4 年

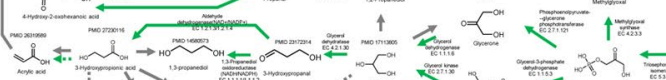

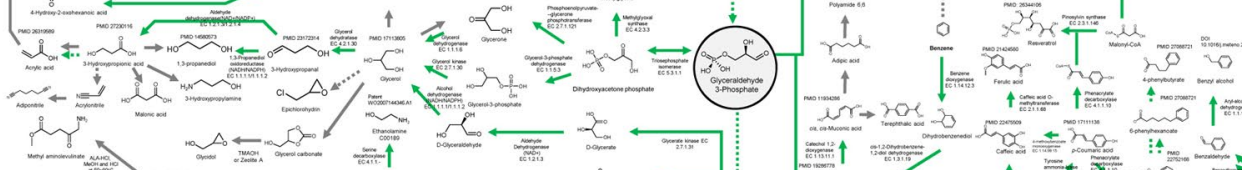

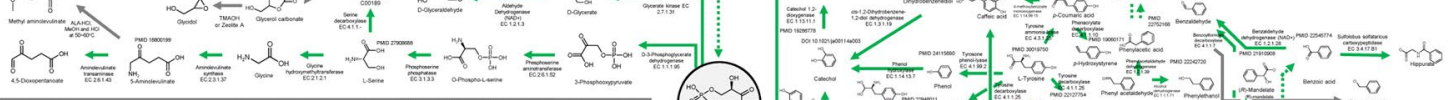

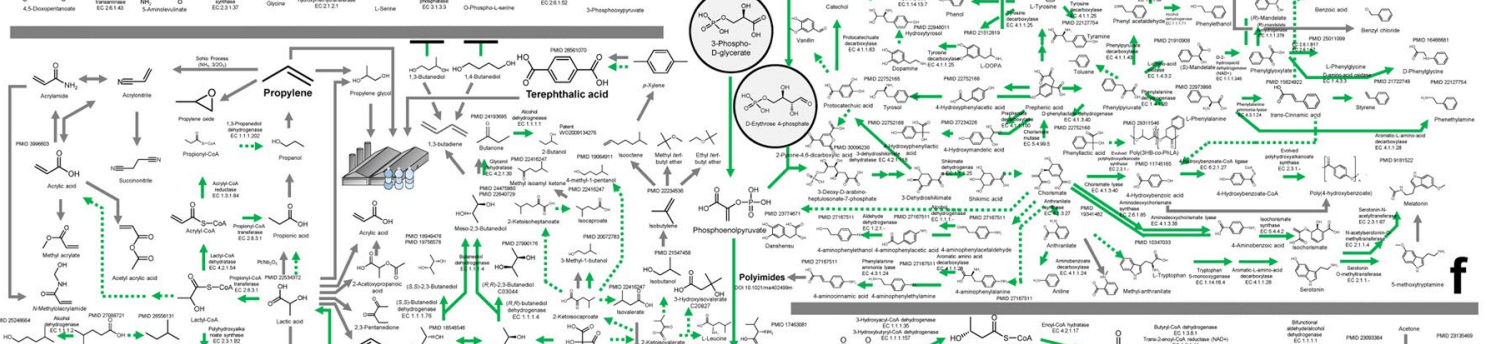
C

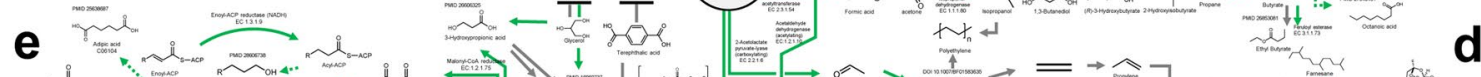

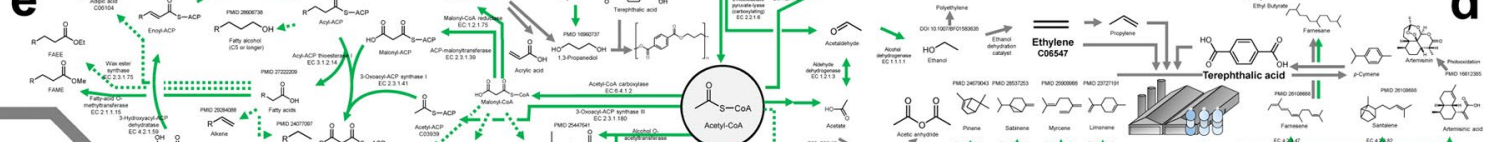
(n)

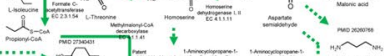

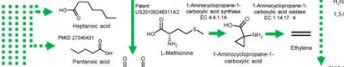

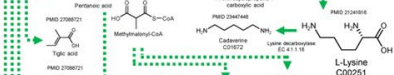

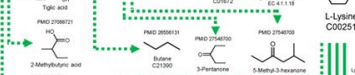

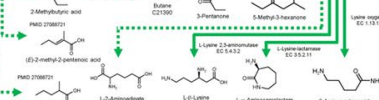
$1-r_{n \rightarrow \infty}$ i $\quad \sin 2$

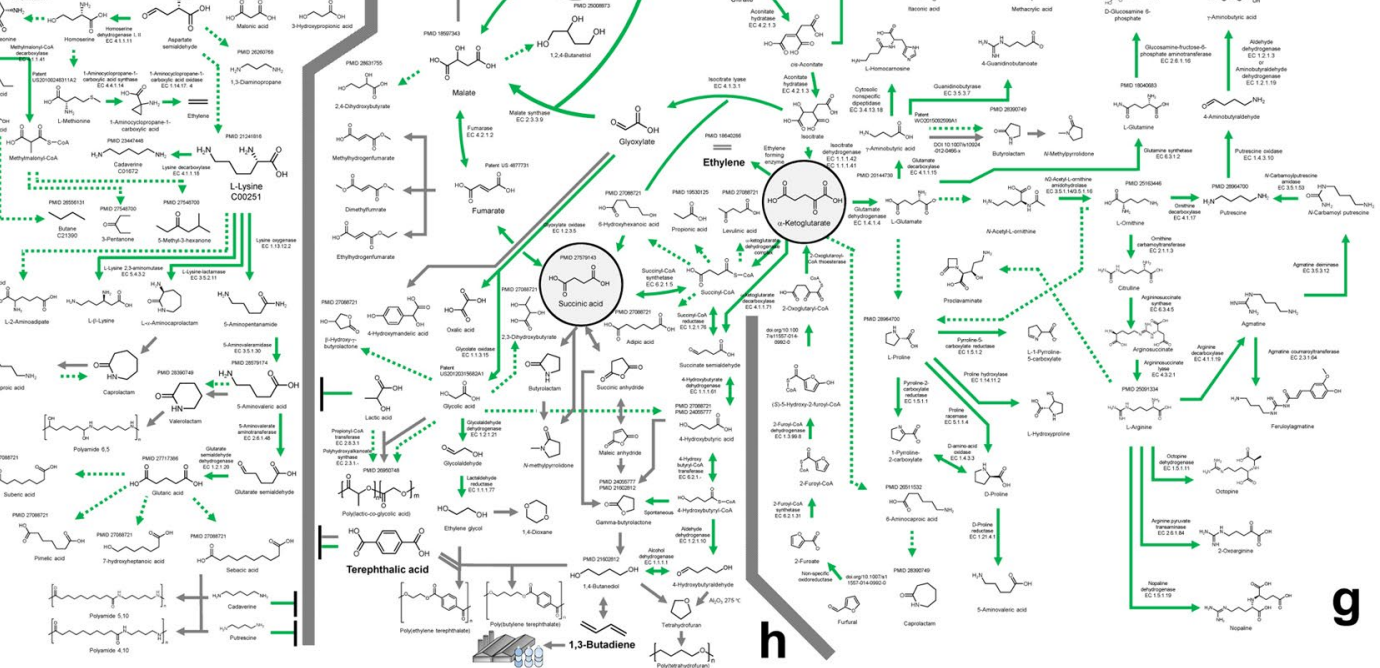




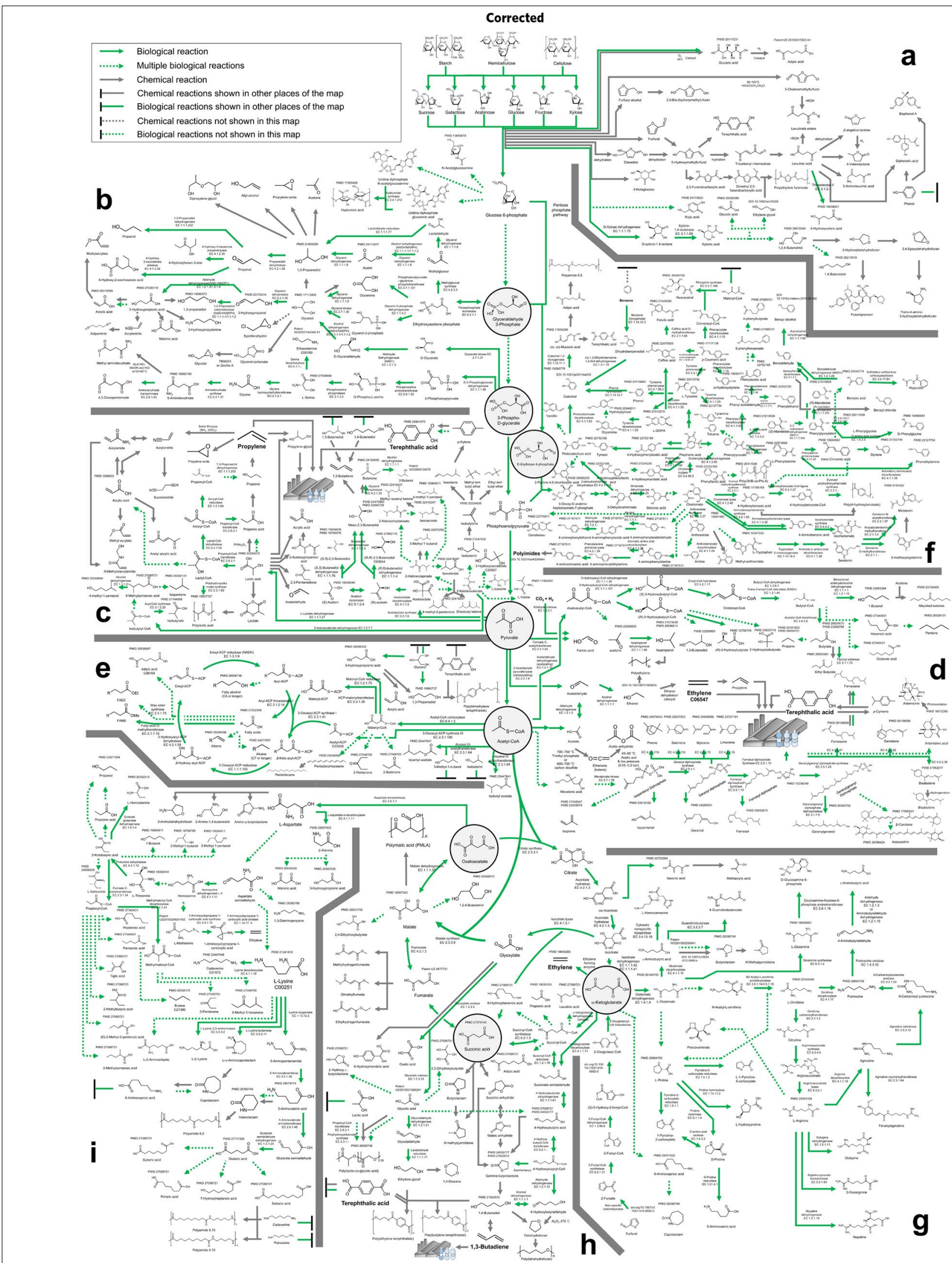

Supplementary Fig. 1 | Original and Corrected.

Published online: 10 September 2019

https://doi.org/10.1038/s41929-019-0358-8 